\title{
Ples i upotreba droga kao značenjske prakse u sociologiji rave-kulture
}

\author{
Rašeljka Krnić \\ Institut društvenih znanosti Ivo Pilar, Zagreb, Hrvatska \\ e-mail: raseljka.krnic@pilar.hr
}

\begin{abstract}
SAŽETAK Potreba za modificiranjem ili odbacivanjem pojma subkulture javlja se početkom devedesetih, uglavnom kao reakcija na pojavu plesne elektronske glazbe i kulture koja oko nje nastaje. Upravo na tom primjeru postavlja se teza o promjenjivoj i kompleksnoj prirodi suvremenih mladenačkih kulturnih praksi, formi i stilova koji, da bi se razumjeli, zahtijevaju novu perspektivu i nove analitičke alate. Osim što su rave-kultura i različite scene elektronske glazbe poslužile kao "teren" na kojem se propituju postavke birminghamske interpretacije subkultura u okviru šire teorijske rasprave o primjenjivosti općih pojmova, kao što su klasa, otpor, stil, itd., neki su se autori pozabavili analizom specifičnih elemenata koji konstituiraju taj mikrosvijet, i to nastojanjem rekonstrukcije organizacijske logike, praksa, rituala, motiva i "struktura osjećaja" koji stoje iza toga mladenačkog pokreta. Rad se bavi pregledom i analizom pojedinih postsubkulturnih koncepata koji iz različitih perspektiva $i$ iz drugačijih teorijskih pozicija analiziraju dvije najvažnije (sub)kulturne prakse kojima je definiran svijet elektronske glazbe i rave-kulture - konzumaciju droga i ples.
\end{abstract}

Ključne riječi: postsubkulturna teorija, rave-kultura, elektronska glazba, ecstasy, droge, ples.

\section{Uvod}

Tijekom sedamdesetih i prve polovine osamdesetih godina 20. stoljeća subkulturni koncept birminghamske škole predstavljao je dominantnu paradigmu u razmatranju povezanosti mladih, stila i glazbenoga ukusa. Međutim, već početkom osamdesetih koncept je podvrgnut određenim kritikama i to od strane nekih autora koji su i sami pisali u okviru "škole". Neke od tih ranih primjedbi na račun subkulturne teorije, kao što je jednodimenzionalni pogled na pitanje otpora, prejako naglašavanje strukturalnih elementa, kao što je klasa, izostanak etnografskoga pristupa u istraživanju, apstraktno poimanje subkulture, imperativ teritorijalnosti, zanemarivanje uloge djevojaka u subkulturama, itd., postat ce temelj za otvaranje sasvim novoga diskursa devedesetih, koji će biti zasnovan, u prvom redu, na kritičkom propitivanju postavki birminghamske škole zbog pojave novih aktera i oblika povezivanja. 
Postbirminghamska razmatranja raznovrsnih životnih stilova i mreža odnosa u kulturi mladih nazvana su postsubkulturnom teorijom, kao zajedničkim nazivnikom za sve nove teorije i koncepte koji se na ovaj ili onaj način referiraju na pojam subkulture. Međutim, radi se o izrazito heterogenom području unutar kojega nastaju teorije od kojih se neke radikalno udaljavaju od birminghamskoga koncepta, zagovarajući potpuno napuštanje pojma subkulture i uvođenje novih analitičkih pojmova, ali i orijentacija koje naglašavaju potrebu za redefiniranjem pojma, pri tome zadržavajući neke njegove značajke kao i dalje upotrebljive i važeće za razumijevanje suvremenih mladenačkih saveza. Potreba za modificiranjem ili odbacivanjem pojma subkulture javlja se početkom devedesetih, uglavnom kao reakcija na pojavu plesne elektronske glazbe i kulture koja oko nje nastaje. Upravo na tom primjeru postavlja se teza o promjenjivoj i kompleksnoj prirodi suvremenih mladenačkih kulturnih praksa, formi i stilova koji, da bi se razumjeli, zahtijevaju novu perspektivu i nove analitičke alate. Osim što su rave-kultura i različite scene elektronske glazbe poslužile kao "teren" na kojem se propituju postavke birminghamske interpretacije subkultura u okviru šire teorijske rasprave o primjenjivosti općih pojmova, kao što su klasa, otpor, stil, itd., neki su se autori pozabavili analizom specifičnih elemenata koji konstituiraju taj mikrosvijet, i to nastojanjem rekonstrukcije organizacijske logike, prakse, rituala, motiva i "struktura osjećaja" koji stoje iza toga mladenačkog pokreta. Ovaj rad bavi se pregledom i analizom pojedinih post-subkulturnih koncepata koji iz različitih perspektiva i iz drugačijih teorijskih pozicija analiziraju dvije najvažnije kulturne prakse kojima je definiran svijet elektronske glazbe i rave-kulture - konzumaciju droga i ples.

\section{Upotreba droga u subkulturnom kontekstu}

Različite vrste droga oduvijek su bile usko povezane s brojnim subkulturnim svjetovima, posebno onim mladenačkim, najčešće posredovanim glazbom i stilom, a vrste i način na koji se koriste važni su elementi kojim se takvi društveni svjetovi definiraju. S jedne strane, uloga droge može biti čisto funkcionalna, u smislu omogućavanja dodatne energije za rad ili dugotrajan ples te kao inspiracija kod kreativnoga stvaranja, a s druge, na simboličkoj razini, odabir određenih droga i načina korištenja izražava specifičan pogled na svijet, posredujući određeni životni stil. Rana džez-kultura, o kojoj je šezdesetih pisao Becker (1997.), bila je neraskidivo povezana s drogama, legalnim i ilegalnim. Mnogi poznati džez-muzičari 40-tih i 50-tih koristili su marihuanu i često bili ovisnici o heroinu i kokainu, a mladi još neprofilirani svirači posezali su za istim drogama misleći da će uz njihovu pomoć svirati bolje i kreativnije (Mignon, 1993.). Subkultura modsa, ranih šezdesetih, također je bila obilježena širokim spektrom droga, koje su imale funkciju povećanja energije, tj. da bi se moglo duže plesati. Također, dobro je poznato kako su droge bile centralni element životnoga stila mnogih pripadnika hipi-pokreta i dok su za modse one imale funkciju fizičkoga stimulansa (najčešce su to bili amfetamini) i uglavnom predstavljale vikend zabavu. U hipi-kulturi droge su bile usko povezane s političkim vrijednostima, pa su halucinogeni poput LSD-a shvaćeni kao sastavni dio otpora i pobune protiv mainstream-normi zapadnoga društva. I za mnoge punkere, 
sredinom sedamdesetih, različiti stimulansi predstavljali su dio subkulturnoga etosa, kao izraz odbacivanja dominantnih vrijednosti i iskazivanja prezira prema establišmentu. Ako uzmemo u obzir činjenicu da droge općenito možemo razvrstati prema različitim kriterijima, a između ostaloga i po kriteriju legalnosti, mladi, kada je u pitanju posezanje za drogama, uglavnom slijede model koji je prisutan i u "roditeljskoj" kulturi. Razlika je u tome što ta "roditeljska" kultura preferira drugačije droge, tj. one koje se smatraju legalnima (na primjer alkohol), bez obzira na razarajuće posljedice koje ima dugotrajno korištenje (Perasović, 2001.). Međutim, prema Perasoviću (2001.), mnogobrojni stereotipi prisutni u javnosti povezuju droge isključivo s onim ilegalnim, često ne praveći razliku između korisnika heroina koji pate od teških posljedica ovisnosti i širokoga spektra upotrebe različitih droga (posebno u subkulturnim krugovima), koja ne vodi tragičnim posljedicama i u tešku ovisnost. Treba naglasiti kako brojni faktori određuju "posljedice" i značenja koje proizlaze iz izrazito diferenciranih oblika korištenja.

"Droge bez sumnje djeluju u skladu sa svojim farmakološkim svojstvima, ali s obzirom na socijalnu i interakcijsku konstrukciju subkulturnog svijeta $i$ značenja, mnoge droge mogu biti različito upotrebljavane, unutar različitoga subkulturnog stila, proizvodeći $i$ različite učinke $i$ uklapajući se u različite modele života $i$ sustave vrijednosti, bez obzira na ista farmakološka svojstva" (Perasović, 2001.:327).

Mnogi autori posljednjih petnaestak godina govore o fenomenu "normalizacije" droga među mladim ljudima, kad korištenje prestaje biti marginalna aktivnost specifičnih značenja vezanih za pobunu i subverziju (što je slučaj s nekim subkulturnim i kontrakulturnim pokretima), nego postaje dijelom svakodnevnoga života različitih skupina mladih (Parker i sur., 1998.:153-7) "normalizaciju" identificiraju kroz nekoliko dimenzija: veća dostupnost; povećano konzumiranje, neovisno o spolu i klasi; raširenost; opća informiranost; ukorijenjenost u slobodnom vremenu. Međutim, identificiranje "normalizacije" samo po sebi ne govori puno jer značenja i efekti koji proizlaze iz korištenja različitih vrsta droga dolaze iz specifičnoga konteksta. Određene supstance vezane su za specifičan kulturni kontekst, s tim da su samo neki oblici korištenja ušli u proces "normalizacije", a za njih su i dalje vezana specifična značenja, iako su se možda promijenila u odnosu na ranija razdoblja. Referirajući se na Matthewa Collina, koji sugerira da droge treba promatrati kao oblik "tehnologije" (što otvara potpuno novi prostor za razumijevanje koncepta "droge" kao kulturno specifičnoga), Gilbert i Pearson (1999.) naglašavaju kako socijalni i kulturni efekti bilo koje tehnologije gotovo potpuno ovise o konkretnom načinu korištenja, koji ne proizlazi samo iz tehnologije nego ovise o sociokulturnom kontekstu koji je proizvodi. Iako je termin "enkulturacije" tehnologije originalno bio korišten da bi opisao fenomen domestikacije medija, kao što su televizija i radio, autori ga primjenjuju kao termin koji određuje mjeru u kojoj je korištenje droga postalo sastavnim dijelom kulture, tj. procesa "normalizacije", a raspon efekata i značenja koja specifična tehnologija, tj. u ovom slučaju droga, proizvodi bit ce definiran kontekstom u kojem se određene prakse odvijaju. 


\section{Ecstacy - faktor "normalizacije"}

Teško bi bilo osporiti činjenicu da je suvremena plesna kultura nerazdvojno povezana s kulturom droge. Brojne studije pokazale su kako mnogi akteri na različitim scenama elektronske glazbe uzimaju ili su uzimali različite legalne i ilegalne supstance (Malbon, 1999.; Thornton, 1996.; Redhead, 1993.). Proces "normalizacije" svoje korijene vuče iz perioda s kraja osamdesetih godina, kada je pojava rave-kulture donijela generalnu promjenu u kulturi droga, zamjenjujući "teške", fizički adiktivne supstance, poput heroina, onima koje neki nazivaju "lakšim" drogama, kao što je ecstacy. Upravo je pojava ecstacyja odigrala vrlo važnu ulogu u pomicanju korištenja droga s margine u centar aktivnosti mladenačkih kultura.

“'Plesna kultura' $i$ 'Kultura ecstasyja' postali su gotovo sinonimi u Velikoj Britaniji. Uspon plesne kulture u Velikoj Britaniji dogodio se istovremeno s eksponencijalnim porastom broja ljudi koji redovito koriste ilegalne droge" (Gilbert i Pearson, 1999.:138).

Iako su različita istraživanja pokazala kako se u klubovima i partyjima na otvorenom koristi čitav spektar droga, poput kokaina, LSD-a, amfetamina i marihuane, sintetička droga MDMA, popularno nazvana ecstasy (iako je dobila i druga, ulična imena specifična za pojedine lokalitete), ipak prevladava kao zaštitni znak rave-kulture, a upravo je njegova rasprostranjenost imala vrlo snažan utjecaj na prakse i prirodu iskustva.

U Sjedinjenim Američkim Državama, početkom sedamdesetih, MDMA se počeo koristiti kao rekreacijska droga, ali je još uvijek bila dostupna samo uskim krugovima i o njoj se vrlo malo znalo. Međutim, nekoliko godina ranije, 1965., dr. Alexander Shulgin, koji je predavao na univerzitetu Berkeley u Kaliforniji, od svojih studenata doznaje o neobičnom djelovanju te supstance i - kako je već neko vrijeme istraživao psihodelična iskustva u okviru farmakologije i psihijatrije, odlučio ju je i sam sintetizirati i ispitati njezino djelovanje. ${ }^{1}$ Shulgin se uglavnom koristio nekonvencionalnim metodama koje često nisu nailazile na odobravanje, tj. droge je testirao na sebi i svojim prijateljima koji su nerijetko i sami bili znanstvenici istraživači, a ne na životinjama, što je do tada bila uobičajena praksa (Wright, 1998.). Psihoterapeut Leo Zeff bio je toliko impresioniran djelovanjem te sintetičke droge da je kao svoju osobnu misiju uzeo zadatak upoznati što više terapeuta diljem Amerike s njenim efektima u liječenju psihičkih tegoba. Neki su psihijatri zaista koristili tu supstancu kao dio terapije (sve dok u Americi 1985. nije postala ilegalna), nalazeći da su mnogi pacijenti uslijed uzimanja propisanih količina pokazali vidan napredak, posebno kada se radi o uspostavljanju komunikacije s drugima (Greer i Tolbert, 1998.)

1 Iako je u početku istraživanja radio u okviru kemijske kompanije Dow (koja mu je nakon što je za njih izumio uspješan insekticid dala odriješene ruke da se bavi čime god želi), eksperimenti s MDMA-om i drugim psiho-stimulansima nastavljeni su u privatnom laboratoriju u njegovoj kući i nakon što ga je Dow prestala financirati zbog "problematične" prirode takvih istraživanja. 
MDMA je s vremenom postala sve popularnija rekreacijska droga, a Alexander Shulgin dobio je kultni status među korisnicima. Ranih osamdesetih u Americi je dobila naziv "Adam" i ušla u popularne noćne klubove u području Dallasa. I dok je u to vrijeme u SAD-u još uvijek bila legalna supstanca, u Velikoj Britaniji je zabranjena već 1971. (Malbon, 1999.). Iako se MDMA počela najprije koristiti u Sjedinjenim Američkim Državama, i to na sličan način kao što se konzumirala marihuana, u kućnoj atmosferi u užim krugovima, (Wright, 1998.), tek će u drugom dijelu osamdesetih u Velikoj Britaniji ova droga, nazvana "ecstasy", postati neraskidivo povezana s elektronskom glazbom i kulturom koja se oko nje razvila. Od toga trenutka do danas ecstasy postaje najpopularnija droga nakon kanabisa, i za razliku od njega gotovo se ekskluzivno koristi u klubovima i na rejvovima kao "plesna droga" (Saunders, 1997.). Studije s kraja devedesetih pokazale su kako od 68 do 76 posto posjetitelja klubova elektronske glazbe u Britaniji redovno uzima ecstasy, i to uglavnom vikendima. Međutim, iako je moralna panika posredovana medijima obilježila dobar dio javnoga diskursa o rave-kulturi, često se zaboravlja kako je samo jedan posto populacije mladih do 30 godina redovno uzimalo ecstasy u određenom periodu, a većina populacije nikada nije probala niti jedan oblik ilegalne droge (Malbon, 1999.).

Mediji su se vrlo rano, gotovo od samih početaka, počeli baviti rave-kulturom. Godine 1988. britanski tabloid The Sun proglasio je rave novim plesnim trendom, ali ubrzo nakon početnoga entuzijazma mediji su, potaknuti s dva smrtna slučaja uzrokovana ecstasyjem, počeli vrlo negativno pisati o novom mladenačkom kulturnom fenomenu. Novine su počele širiti do tada neviđenu moralnu paniku zbunjujućim i često pretjeranim izvještajima, napuhanim naslovima i pozivima na policijsku akciju. U lipnju 1989. Daily Mail tvrdi kako je "Acidhouse fasada za dilanje droga najgore vrste u golemim razmjerima i kako se radi o ciničnom pokušaju da se mlade ljude navuče na drogu pod krinkom veselih glazbenih događaja" (Collin i Godfrey, 1997.:97). Mediji su tijekom devedesetih uporno dizali paniku izvještavajući o ecstasyju kao najgoroj pošasti koja razara mlade živote. Međutim, medijska se buka u dobroj mjeri stišala kad su se ilegalni rave-partyji preselili u kontrolirane prostore klubova, a čak su i povremene smrti navodno uzrokovane ecstasyjem bile tretirane kao izolirani incidenti. U slučaju ecstasyja, negativna i prenapuhana medijska izvještavanja, potaknuta komercijalnim interesima zarade, zapravo su potaknula, a ne obeshrabrila, mlade ljude da eksperimentiraju s tom drogom (Thornton, 1996.).

\section{Elektronska glazba i droge: rizik i solidarnost}

Centralni argument negativne društvene reakcije na rave-kulturu odnosi se na izloženost moralnom i fizičkom riziku koji proizlazi iz konzumiranja droga. Diskurs javnoga zdravstva uglavnom se temelji na etiketiranju rave-kulture kao miljea u kojem prevladava ekstenzivno konzumiranje droga, upozoravajući na brojne društvene i zdravstvene rizike koje proizlaze iz takvih praksi (Yacoubian i sur., 2004.; Kelly, 2005.). Međutim ovaj tip diskursa predstavlja vrlo pojednostavljenu i parcijalnu perspektivu najčešće oblikovanu javnim politikama prema rejvu, koji se često izjednačava s ilegalnom kulturom droge, svodeći ga na taj način na jednodimenzionalnu kulturu rizika. Stavljajući naglasak isključivo na potencijalne fizičke i psihološke 
zdravstvene rizike, sasvim se zanemaruje dimenzija značenja koja proizlaze iz takvih praksi koje igraju vrlo važnu ulogu u procesima identifikacije i konstrukcije grupnoga identiteta i specifičnoga životnog stila, u ovom slučaju vezanoga za različite scene elektronske glazbe. ${ }^{2}$ Kao što je već rečeno, studije zdravstvenih rizika vrlo su često fokusirane na negativne posljedice, zanemarujući neke druge, ne nužno negativne aspekte eksperimentiranja s ecstasyjem, o kojima svjedoče brojni pripadnici scene i koje ističu neki od teoretičara koji su se bavili ovom temom izvan okvir proučavanja potencijalnoga zdravstvenog rizika.

Međutim, i unutar rasprava koje u središte interesa stavljaju kulturne aspekte prakse konzumacije droga unutar rave-kulture nailazimo na različita stajališta i fokuse analize. Ono što čini temelj rave-kulture je iskustvo posredovano glazbom, plesom i vrlo često drogom. Takva iskustva predstavljaju mnogo više od samoga zbroja njegovih elemenata i proizlaze iz kompleksne isprepletenosti različitih praksa, od kojih svaka igra bitnu ulogu, a droga je, uz glazbu i ples, neupitno jedna od njih. Brojne teorijske orijentacije koje su se pojavile početkom devedesetih godina (postsubkulturne teorije), kao odgovor i najčešće kritika subkulturne teorije "birminghamske škole" koja je dominirala 70-tih i u prvom dijelu 80-tih godina, ${ }^{3}$ donijele su niz različitih interpretacija ponekad istih subkulturnih praksa, pa je tako i odnos prema ulozi i značenju ecstasyja kao najpopularnije droge rave-kulture raznovrstan.

Farmakološko svojstva MDMA-a potiču otpuštanje veće količine serotonina i dopamina u mozgu nego što je to uobičajeno, čime direktno utječe na raspoloženje i stanje svijesti. Mnogi koji su tu drogu uzimali svjedoče o sličnim iskustvima o kojima je govorio i sam Shulgin opisujući izrazito ugodan, ponekad euforičan osjećaj praćen povećanom empatijom i snažnom povezanošću s drugima, ali i velikom količinom fizičke energije koja omogućava dugotrajno plesanje. Neki autori primjećuju kako djelovanje ecstasyja potiče ljude na povećanu kooperativnost i solidarnost zbog koje dolazi do ukidanja društvenih granica (rasne, spolne, etničke, dobne i druge predrasude) uobičajenih u široj društvenoj strukturi (Wright, 1998.; Kavanaugh i An-

2 U raspravu o "objektivnim" zdravstvenim rizicima vezanim za konzumaciju ecstasyja u ovoj analizi nećemo posebno ulaziti, ali ćemo samo kao zanimljivost spomenuti Saundersov (1995.) izračun po kojem je mogućnost smrtnoga slučaja od uzimanja ecstasyja otprilike jedan naspram sedam milijuna, što je mnogo manje nego kod nekih mainstream aktivnosti, poput skijanja, ronjenja ili svakodnevne vožnje autom. Međutim, ne treba zaboraviti da između krajnje neštetnosti i smrti postoji cijeli spektar potencijalnih rizika vezanih za konzumaciju različitih droga, pa tako i ecstasyja.

3

3 Od druge polovice osamdesetih sve više autora, istražujući raznovrsne životne stilove i mreže odnosa u kulturi mladih, odbacuje djelomično ili čak potpuno postavke proizašle iz birminghamske škole. Mada će se termin "postsubkulturno" pojaviti već kod Chambersa 1987. godine, u subkulturni diskurs uvest će ga, sredinom devedesetih, Polhemus (1996.) i Muggleton (1997.). "Postsubkulturne teorije" zajednički je naziv za cijeli spektar koncepata i teorija s početka devedesetih, koje se i dalje bave sličnim fenomenima okupljanja mladih, ali koje više ne insistiraju na zaključcima i pojmovnom aparatu subkulturnoga koncepta. Postsubkulturno zapravo je najčešće postbirminghamsko jer nove orijentacije grade teorije referirajući se uglavnom kritički na istraživanja iz sedamdesetih. 
derson, 2008.; Hutson, 1997.). Promjena u ponašanju izazvana ecstasyjem donijela je svojevrsnu revoluciju, ali ne u smislu političkoga angažmana i pokušaja svrgavanja vlasti, već revoluciju koja podrazumijeva stjecanje osobne moći i stvaranje prostora solidarnosti. Iako je iskustvo potaknuto ecstasyjem do odrectene mjere individualno - i utoliko su neki o njemu pisali kao izrazito narcističnom i egoističnom, ono se najčešce događa u kolektivu koji je za mnoge presudan faktor zbog osjećaja pripadanja i povezanosti kao centralnoga aspekta cjelokupnoga iskustva. Akademski diskurs o rave-kulturi koji polazi od postmoderne perspektive, naglašavajući gubitak značenja i nostalgiju suvremenih oblika zabave, konzumaciju ecstasyja interpretira kao element hedonističkoga, privremenoga bijega od realnosti. Za Redheada (1993.:7), konzumacija te droge povezana je isključivo s potragom za individualnim zadovoljstvom i predstavlja "bedonizam u teškim vremenima", užitak koji je sam sebi svrha. Interpretirajući Acidhouse pokret kao kulturu "nestajanja" i "zaborava", Melechi (1993.:37) ecstasy vidi kao instrument koji pridonosi iskustvu koje je samo "fantazija oslobođenja i bijeg od identiteta". Izrazito negativan stav iskazuje i Simon Reynolds (1997.) optužujući "farmakološku realnost" ecstasyja za prelazak rave-kulture na "mračnu stranu", koja reflektira posljedice dugotrajnoga uzimanja ecstasyja i očitoga pada kvalitete droge. Međutim, čak i neovisno o pretpostavljenom slabljenju efekta, za Reynoldsa, kao i za Melechija, iskustvo zajedništva, solidarnosti i ljubavi o kojoj rejveri govore, u načelu je besmisleno, ispražnjeno od značenja, površno i ne vodi nikamo, osim u prazninu. Za Reynoldsa je rave-kultura - kultura bez sadržaja, potraga za fascinacijom, a ne značenjem, dok je ecstasy samo još jedan element hiperstimulacije koja ne vodi nikamo.

S druge strane, neki autori smatraju kako droge predstavljaju jedan od oblika kulturne potrošnje koje nemaju toliko veze s potrebom da se izlaže nepotrebnom i nepredvidivom riziku, već služe potrebi aktivnoga održavanja osjećaja stabilnosti.

"Upotreba droga od strane mladih ljudi, osobito u klubovima, predstavlja način na koji mladi ljudi mogu imati nekakvu kontrolu nad svojim svakodnevnim životima. upotreba droga predstavlja aktivno izražavanje načina na koji se mladi ljudi nose sa zabtjevima socijalnih struktura unutar kojih djeluju" (Moore i Miles, 2004.:507508).

Općedruštveni, ali i dijelom akademski, diskurs pitanje konzumacije droge analiziraju u okvirima "patologije", a mlade se ljude često prikazuje kao bespomoćne žrtve zavedene drogom. Međutim, vrlo je malo istraživanja koja se bave "seciranjem" samoga iskustva rave-partyja i uloge koju droga ima u procesu identifikacije. Da bi ušli u srž pitanja što uopće droge znače za mnoge mlade ljude koji vikende provode plešući u klubovima ili na otvorenim partyjima, Moore i Miles u fokus istraživanja smještaju uobičajne, rutinske prakse koje se odvijaju na samom partyju, prije i nakon njega. Između ostaloga, dolaze do zaključka kako je konzumiranje droge u kontekstu rave-kulture i partyja po prirodi strateškoga karaktera jer se radi o svjesnom odabiru nečega što im pomaže da postignu osjećaj pripadnosti određenoj specifičnoj strukturi, koja je razvila svoj jezik i praksu, a stoji izvan uobičajene svakodnevnice. Iz Mooreovoga i Milesovoga rada proizlazi kako cjelokupno iskustvo rejva ne predstavlja puki bijeg od svakodnevnice, kao što to sugeriraju Melechi ili Rietveld, već je 
to njen produžetak ili čak protuteža realnosti. Iako je konzumacija droga povezana s različitim društvenim problemima, vrlo često se zanemaruje dimenzija za koju bi se čak moglo reći da predstavlja tabu, a koja se odnosi na pozitivne efekte eksperimentiranja s drogama i na iskustava koja mogu pridonijeti društvenoj prilagodbi i osobnom razvoju.

U izrazito detaljnoj i temeljitoj studiji britanske scene elektronske glazbe i praksi rave-kulture, Ben Malbon (1999.) bavio se, između ostaloga, i ulogom MDMA-a, kao nezaobilaznoga sastojka klupskoga iskustva. Kroz ples, glazbu, interakciju i osobnu ekspresiju, proizvodi se euforičan osjećaj koji Malbon naziva oceanskim iskustvom, a da bi se takvo stanje dodatno intenziviralo i produžilo, mnogi posjetioci klubova koriste ecstasy. Oceansko iskustvo potaknuto korištenjem različitih droga nazvano je ekstatičnim iskustvom. Oceansko iskustvo, pokazuje njegova, ali i neke druge studije, moguće je postići i bez MDMA ili neke druge supstance, tako da se zapravo radi o dodatnom emocionalnom sloju, koji podržava ostale tjelesne prakse. Treba napomenuti da Malbon nije jedini autor koji ecstacy ne vidi kao definirajući faktor iskustva. Npr. Georgina Gore (1997.) dolazi do zaključka kako razina sreće i zadovoljstva tijekom partyja ne ovisi toliko o tome konzumira li se droga nego koliko se redovito posjećuju takva okupljanja, s tim da se količina zadovoljstva povećava s učestalošću i iskustvom. I Maria Pini (1997.), poput Malbona (1999.), konstatira centralnu ulogu ecstacyja tijekom "pomaknutih" iskustava, ali tvrdi kako im on nije jedini uzrok jer su mnoge žene koje je intervjuirala u svojoj studiji o ženskoj perspektivi unutar rave-kulture opisivale takva iskustva, ali bez korištenja droga.

Vrlo se često može čuti kako je upravo ecstasy odgovoran za stvaranje rave-kulture i kako je bez njega možda nikad ne bi ni bilo. Međutim, s obzirom na činjenicu da je ecstasy sintetiziran već početkom 20. stoljeća, a u rekreativnu upotrebu ulazi već krajem šezdesetih, očito je da je bio potreban specifični kulturni kontekst definiran mnogim drugim faktorima (koji se dogodio tek krajem osamdesetih) da bi ta droga postala dijelom novoga mladenačkog kulturnog pokreta, pa tvrdnje o takvoj vrsti determinizma djeluje prilično pojednostavljeno i nedorečeno. Prakse vezane za konzumaciju droge gotovo su uvijek kompleksne i pretpostavljaju različite vještine, tehnike i određene kompetencije koje se bitno razlikuju s obzirom na "staž", ali i tip scena na kojima se takve prakse odvijaju. Svi ti elementi utjecat će na oblik iskustva koje će pojedini akteri doživjeti. Takve aktivnosti itekako proizvode značenja koja utječu na konstrukciju i transformaciju identiteta koja se odvija tijekom i pod utjecajem ekstatičnih stanja i čiji efekt ne prestaje u trenutku izlaska iz kluba.

"Daleko od neke vrste bezumnoga i besmislenoga hedonizma, kakav se često prikazuje u popularnim (pogrešnim) prezentacijama clubbinga, čini se da doživljavanje ekstatičnih osjećaja može biti izvanredno $i$ za mnoge neusporedivo i iznimno vrijedno doživljavanje vlastitoga identiteta. Osobito je važno što to doživljavanje identiteta clubberi smatraju svojim 'pravim' identitetom - kakvi doista jesu" (Malbon, 1999.:127).

Oceansko iskustvo temelji se na osjećaju povezanosti i solidarnosti koji, iako postignut u trenutku, predstavlja mnogo više od prolazne, kratkotrajne okolnosti. Radi 
se o kontinuiranom elementu identiteta osnaženom kroz različite prakse i socijalnu interakciju koja se odvija tijekom takvih okupljanja.

Ranije spomenuta istraživanja iz perspektive zdravstvenih rizika rijetko ce se baviti kulturnim aspektima konzumacije droge, a onda kada se i razmatra fenomen solidarnosti na rave-partyjima, porijeklo i značaj toga aspekta grupnoga identiteta uglavnom se svodi na sintetičku nuspojavu farmakološkoga efekta ecstasyja (Mosler, 2001.). Slično stajalište, kao što smo mogli vidjeti, zauzima i Reynolds (1997.:105) da bi podupro svoju tezu o rejvu kao kulturi bez značenja, čija je sudbina "gotovo kemijski programirana u MDMA-u”. Mnogi autori koji su iz različitih perspektiva bave scenama elektronske glazbe pisali su o specifičnoj formi solidarnosti i tzv. PLUR-etosu (Mir, Ljubav, Jedinstvo, Poštovanje), koji se mogu pronaći u takvom tipu zajednice (Hutson, 1997.; Thornton, 1996.; Bennet, 1999.; Malbon, 1999.). Iako je fragmentacijom scene, uslijed komercijalizacije i pojave novih stilova takav etos donekle ukinut, treba reći kako određeni aspekti prvotnih normi postoje i danas na nekim dijelovima scene, a osjećaj solidarnosti i povezanosti o kojoj mnogi rejveri govore prouzrokovan je različitim faktorima i samo je parcijalno uvjetovan drogama. Za mnoge participante iskustvo rejva povezano je s ecstasyjem, ali za neke aktere ono nadilazi puki farmakološki efekt koji takvo iskustvo ne definira, nego ga samo nadopunjuje i pomaže pri uspostavljanju afektivne solidarnosti koja proizlazi iz niza drugih zajedničkih aktivnosti u kojima akteri sudjeluju, a što se posebno odnosi na ples koji predstavlja centralnu praksu rave-kulture.

\section{Ples kao značenjska praksa}

Povijest ljudske civilizacije neupitno je i povijest plesa. Kroz gotovo sve poznate kulture ta društvena praksa zauzima vrlo važno mjesto u socijalnoj strukturi, kao oblik ljudske ekspresije kroz pokret. Međutim, plesanje daleko nadilazi svoju fizičku manifestaciju ili isključivo estetsku dimenziju, posredujući niz značenja i simboličkih aspekata određene kulture i društva. Bez obzira što se radi o tjelesnoj i simboličkoj praksi koja zauzima tako važno mjesto u ljudskoj civilizaciji jer "čini se kako ljudi svugdje plešu" (Sparshott, 1995.:3), javni i akademski diskurs, paradoksalno, skloni su zanemariti mnoge aspekte plesa, a posebno one koji nadilaze njegov utilitarni karakter. Iz antropološke perspektive ples se često definira kao kulturna praksa i društveni ritual koji predstavlja oblik estetskoga zadovoljstva i sredstvo pomoću kojega se uspostavljaju veze i specifične strukture unutar zajednice (Pušnik i Sicherl, 2010.). Međutim, iako su antropološke analize plesa raznovrsne, ono što ih povezuje pokušaj je da se njegova semiotika iščitava kao jezik kojem je svrha da nešto označi, tj. ples mora imati konkretnu funkciju. Akademski diskurs oduvijek se snažno odupirao bilo kakvoj ideji da se ples tumači kao praksa koja transcendira ulogu sredstva, ostajući na razini analize koja ga interpretira kao simbolički instrument koji služi učvršćivanju socijalne strukture i regulacije ponašanja (Gilbert i Pearson, 1999.). Drugim riječima, kada interes za fenomen plesanja i postoji, on se uglavnom odnosi na identificiranje njegovih racionalnih aspekata. Generalno je stajalište velikoga broja onih koji pišu o plesu da su takve prakse u kulturi zapadne civilizacije marginalizirane upravo zbog svoje neracionalne prirode i da je takav odnos prema plesu dio 
širega kulturnog sindroma prezira prema tijelu. Judith Lynne Hanna sugerira kako je dugotrajno izbjegavanje plesa kao ozbiljnoga predmeta analize povezano s kombinacijom "puritanske etike, socijalne stratifikacije, koncepta muževnosti $i$ otklona od neverbalnog ponašanja" (Hanna, 1987.:9). Na istom tragu Ward upozorava kako Polhemusova konstatacija o "atrofiji resursa tjelesne komunikacije" zbog ovisnosti o verbalnim vještinama ne drži vodu, već se "atrofija" događa zbog načina na koji se tretira tijelo: "to što određeni oblici diskursa određuju naš djelokrug ne znači da vokabular i sintaksa tjelesne komunikacije nestaju"(Ward, 1997.:8). Funkcionalističke interpretacije plesnih kultura odvijaju se pod utjecajem racionalističkoga imperativa, suprotstavljenoga "iracionalnim" tjelesnim ekspresijama, insistirajući na funkciji i svrsi kao primarnim vrijednostima, u odnosu na trenutno tjelesno zadovoljstvo koje je sebi samom svrha.

Različite etnografske studije pokazale su da postoje određene teškoće kod pokušaja da se iskustvo plesanja verbalizira pomoću postojećih lingvističkih kategorija, što između ostaloga navodi Warda (1993.) da zaključi kako se radi o praksama koje na neki način stoje izvan falocentričnih granica racionalizma. I neki su drugi autori iz filozofske perspektive koncept plesanja razmatrali kao odmak i alternativu falocentričkoj reprezentaciji ljudske subjektivnosti. ${ }^{4}$

Pitanje značaja koje se pridaje određenoj kulturnoj praksi uvijek je povezano s pitanjem značenja koje se s tom praksom povezuje. Plesna je glazba u popularnoj kulturi gotovo uvijek tretirana kao inferiorna onoj koja je namijenjena za slušanje jer se na ples često gleda kao na aktivnost kojoj nedostaje "Ozbiljan" sadržaj. Iako je rock and roll nastao kao glazba uz koju se pleše, šezdesetih se godina promiče u "Ozbiljnu" umjetničku formu i od toga se trenutka zauvijek odriče plesa, što mu omogućuje tretman respektabilne kulturne i umjetničke forme. Upravo takav odmak pomiče rock s margine u centar suvremene zapadne kulture, podržavajući njene dominantne vrijednosti (Gilbert i Pearson, 1999.).

Dominantne glazbene vrijednosti preferiraju naglasak na melodiju i vokal, što proizlazi iz logocentričkoga karaktera zapadne kulture, pa je rock kao glazba koja se temelji na otpjevanoj "poruci" tretiran kao glazbena i kulturna praksa koja posjeduje značenje i time zavrjeđuje status važnoga kulturnog fenomena, između ostaloga vrijednog akademskog razmatranja, dok su, s druge strane, plesni stilovi popularne kulture rijetko dobivali takav tretman. Pitanje interpretacije značenja kulturnih praksi uvijek za sobom povlači niz problema, pogotovo kad se radi o praksama poput plesa koji je isključivo baziran na pokretu, tj. tjelesnoj ekspresiji. Već je ranije napo-

${ }^{4}$ Pa tako, na primjer, Luce Irigaray (1989.) koristi ples kao metaforu pomoću koje želi pokazati način na koji žensko dijete otkriva svoju subjektivnost, ali pomoću pojmova koja ne pretpostavljaju falocentrički model konstruiran kroz dualizam subjekt-objekt. I Derrida (1991.) piše o plesu kao praksi koja može destabilizirati postojeće seksualne kategorije, omogućavajući izmicanje "nadzoru". Oba filozofska koncepta su apstraktni modeli koji nude alternativni jezik za razumijevanje ljudske subjektivnosti, u čiju problematiku ovdje nećemo dublje ulaziti, ali bitno je reći da ples koji se u ovim slučajevima tretira kao metafora služi za propitivanje i dekonstrukciju dominantnoga diskursa upisanoga u tijelo. 
menuto da su razne studije pokazale kako postoje teškoće u pokušaju verbalizacije osjećaja i značenja u tom kontekstu, što može voditi pogrešnom zaključku da ples ne posjeduje značenja. Međutim, lingvistička kompetencija plesača koji pokušava govoriti o plesu ili promatrača koji ga interpretira, nevažna je jer značenje ne proizlazi isključivo iz mogućnosti verbalizacije. Ples posjeduje značenja koja proizlaze iz različitih tumačenja, a koja će se razlikovati s obzirom na poziciju iz koje tumačimo. Međutim, da bi se zaista moglo govoriti o plesu kao značenjskoj praksi, treba razmatrati njegovo inherentno značenje, autonomno u odnosu na vanjske interpretacije. „Može se reći da su plesni događaji sami po sebi smisleni kada imaju značenje koje postoji neovisno od značenja koje ti događaji imaju za kritičare i promatrače" (Ward, 1997.:17). Drugim riječima, ono na što treba staviti naglasak je značenje koje plesanje ima za one koji plešu. Radi se o kulturnoj praksi koja uvijek pripada određenom društvenom kontekstu iz kojega proizlaze i specifična značenja i kao takva zaslužuje ozbiljna analitička razmatranja, s fokusom na otkrivanje inherentnih značenja, te prihvaćanje ideje da značenje može ležati u plesanju samom po sebi.

Značenja koja proizlaze iz različitih oblika plesanja nisu uvijek fiksirana i jasna, niti se mogu objasniti kao isključivo vezana za neku konkretnu racionalnu funkciju. Čak i za individuu koja pleše refleksivne interpretacije mogu biti difuzne i varirati s obzirom na niz faktora koji čine kontekst.

\section{Ples u rave-kulturi - nadilaženje "racionalnoga"}

O rave-kulturi počelo se pisati gotovo simultano s njenim nastankom, međutim početne analize, naizgled paradoksalno, nisu se posebno bavile onim što je vrlo očito bila i još uvijek jest pokretačka snaga i centralna aktivnost toga pokreta, a to je ples. Kontinuirano dugotrajno plesanje, koje ponekad traje i danima, osnovni je i najvažniji element rave-kulture, a mnoge druge ekspresije, prakse i rituali koji definiraju različite scene elektronske glazbe neodvojive su od plesa te se često odvijaju upravo u službi te aktivnosti. Na samom početku Acidhouse pokreta 1988. i 1989. godine u novinskim tekstovima često se izražavalo čuđenje takvim praksama, naglašavajući kako je teško povjerovati da netko želi putovati kilometrima daleko samo da bi plesao na nekom polju ili u napuštenom skladištu jer to je "izvan granica razuma" (Ward, 1993:28). Gilbert i Pearson (1999.:16) također primjećuju kako "odbijanje disca ili acidhousea da sublimiraju zadovoljstvo u bilo koju drugu funkciju izaziva zabunu i/ili bijes onib koju ne mogu smjestiti tu aktivnost u nijednu moralnu funkciju”. Kao što je već rečeno, vrlo se malo teoretičara bavilo isključivo ulogom i značenjem plesa u rave-kulturi, već ga se uglavnom usputno spominjalo u okviru šire interpretacije značenja cjelokupnoga fenomena i kulture. Kada je pitanje morala i ostavljeno po strani, ples je praksa koja se tumači u okviru šire rasprave o (a)političnosti, što i dalje implicira potrebu da se identificira neko eksterno značenje koje se posreduje plesom. Pa je tako, sukladno tumačenju rave-kulture kao izrazito apolitičnoga fenomena, za Rietveld (1998.) čin plesanja sam po sebi apolitičan i amoralan. Za autoricu se ovdje radi isključivo o "kolektionoj predaji ritmu" potpomognutoj kemijskim stimulansima, pa je i čin plesanja interpretiran kao "slavljenje velike praznine" (Rietveld, 1998.:266). Nadalje, prema Rietveld, glazba i droge omo- 
gućuju dugotrajno plesanje koje može dovesti do "iščezavanja ega u masi tijela koja plešu", ali čak i onda kada autorica dozvoli da "gubljenje sebe može pružiti potencijal za promjenu" naglašava kako "repetitivni zvuci mogu izazvati neku vrstu poslušnosti ritmu, no ne nameću racionalni fokus" (Rietveld, 1998.:267). Isticanje nedostatka racionalnoga cilja te konstatacija nemogućnosti da se plesanjem "promjeni svijet" zaustavlja bilo kakav daljnji pokušaj da se ples "oplemeni" značenjem. Rietveld nije jedina teoretičarka koja tu kulturnu praksu interpretira kao bijeg od stvarnosti. Iz analiza S. Redheada (1993.), S. Raynoldsa (1997.) i A. Melechija (1993.) također se može vidjeti kako ti autori ples, u okviru rave-kulture, interpretiraju kao oblik eskapizma. Međutim, za razliku od takvih shvaćanja, Toshiya Ueno (2003.) techno-plesanje interpretira kao nekonvencionalni oblik otpora i kao takav ples je politična praksa. Njegova interpretacija oslanja se na pojam mimeze koji u mnogim sociološkim i filozofskim teorijama predstavlja temelj konstrukcije društva. Međutim, za razliku od tradicionalnoga poimanja, Uenova primjena pretpostavlja mimezu utjelovljenu u plesnoj glazbi kojoj nedostaje specifični, originalni model koji se imitira, što dovodi do otvaranja karakterističnoga kulturnog i političkoga prostora koji ne podliježe uobičajenim normama. Određeni stilovi plesa vezani za određeni tip elektronske glazbe gotovo da se uopće ne razlikuju, bez obzira promatra li se rave-party u Tokyju ili negdje u Indiji, pa autor zaključuje kako originalni model zapravo ne postoji. Drugi pojam kojim se autor služi je pojam "performativnosti", koji posuđuje od Judith Butler. Performativnost se bazira na ponavljanju određenih rituala, normi i kulturnih kodova koji na taj način konstruiraju identitete, s naglaskom na nepostojanje ontološke "jezgre" . Ueno takvo poimanje performativnosti primjenjuje na model techno-plesa "u kojem je sam original već kopija otvorena beskrajnom ponavljanju gesta" (2003.:107). U tom smislu mimeza plesa je performativna aktivnost putem koje se otvara prostor u kojem su mogući alternativni modeli komunikacije i društvenosti koji predstavljaju otklon od uobičajenih normi ponašanja, pa se u tom kontekstu ples iščitava kao specifična varijanta otpora etabliranim kulturnim kodovima.

Nešto drugačiju analizu plesa u rave-kulturi ponudio je Ben Malbon (1999.), s posebnim naglaskom na kompleksne performativne aspekte, čije bi razmatranje trebalo omogućiti dublji uvid u samu prirodu klupske kulture. Specifične prakse plesa vezane za klubove elektronske glazbe autor konceptualizira kao "ekspresivni oblik razmišljanja, osjećanja i procesuiranja, koji se može reflektirati i konstituirati kroz čvrst odnos između clubbera $i$ klupske scene, kao i između klupske scene $i$ društva čiji je dio" (Malbon, 1999.:86). Prakse plesa u ovom kontekstu zahtijevaju dublje razumijevanje zbog najmanje tri razloga: a) predstavljaju temelj društvene interakcije za mnoge mlade ljude; b) igraju vrlo važnu ulogu u procesu konstrukcije identiteta te upravo iz tog razloga predstavlja važnu kulturnu praksu u svakodnevnom životu, a samim tim i u društvu u cjelini. Koncentrirajući se na performativne aspekte, uočen

5 Judith Butler (1990.) pojam performativnosti koristi u kontekstu konstrukcije rodnih identiteta. Biološke datosti nevažne su jer se rod konstituira kroz neprekidne i ponavljajuće stilizacije tijela, tj. tijelo je diskurzivno, formirano kulturnim i ideološkim regulacijama. Takvo stilizirano i konstruirano ponašanje tijela, koje se neprekidno ponavlja, stvara privid esencijalne, ontološke "jezgre" koja čini rodni identitet. U tom smislu Butler interpretira spol kao performativni akt. 
je niz nepisanih kodova, pravila, simbola i običaja specifičnih za plesanje na ravepartyjima, a koji se odvijaju kroz nekoliko međusobno povezanih dimenzija koje konstituiraju iskustvo plesa: teritorijalizacija i regionalizacija; medijacije; tehnike $i$ kompetencije; emocije. Kratko ćemo prikazati specifičnosti i značenja svake od navedenih dimenzija.

Teritorijalnost i regulacija odnose se na snalaženje u prostoru kluba koji je najčešće podijeljen u različita područja, a tu se misli na plesni podij, prostor pred šankom, WC-e, ponekad prostor za jedenje, predvorje, dio za sjedenje, itd. Iako je za većinu posjetitelja centralni prostor kluba plesni podij na kojem će provesti najviše vremena, povremeno ce se kretati i u ostalim dijelovima kluba, a način na koji se treba ponašati u pojedinim dijelovima reguliran je nizom nepisanih pravila i "konvencija".

Sljedeća dimenzija koja konstituira iskustvo plesa su medijacije, a odnose se na niz efekata koji stvaraju specifičnu atmosferu na svakom partyju. Najvažnija među njima je glazba koja najdirektnije utječe na sve dimenzije plesa. Tip glazbe, promjena ritma, zvučni efekti, itd., mogu radikalno promijeniti ekspresivnu formu plesa.

Tebnike $i$ kompetencije odnose se na način korištenja tijela unutar ograničenoga vremena i prostora čije se karakteristike tijekom noći stalno mijenjaju. Uspješno menadžiranje tijela pretpostavlja prepoznavanje svake specifične situacije i upotrebu tehnika koje tom specifičnom trenutku odgovaraju. Biti na plesnom podiju ne znači samo plesati sam na mjestu nego je konstantno prisutna određena vrsta interakcije s drugim plesačima na podiju, pa će kretanje u prostoru ovisiti o broju ljudi, potencijalnom korištenju različitih tipova droge, glazbi, itd. Način na koji se pleše šalje određenu poruku i igra bitnu ulogu u uspostavljanju interakcije s drugima oko sebe. Način na koji se koristi tijelo u interakciji s okolinom utjecat ce na prirodu i stupanj identifikacija i time na (re)konstrukciju društvenoga, ali i vlastitoga identiteta.

Posljednja dimenzija kroz koju Malbon konstruira plesno iskustvo odnosi se na emotivni aspekt koji proizlazi iz kompleksne interakcije prethodno opisanih dimenzija s pojmovima identiteta i identifikacije. Ova je dimenzija posebno važna za iskustvo plesa jer je on istovremeno njen uzrok i posljedica. "Emocije se izražavaju kroz tijelo, a ipak se istovremeno ulijevaju kroz pokrete tijela, zajedno s glazbom i drugim posrednicima" (1999.:99). Tek kada posjetitelj kluba postane dovoljno siguran i kompetentan u snalaženju u prethodno navedenim praksama, vrlo ugodno emocionalno iskustvo kroz ples dolazi kao nagrada.

U Malbonovoj analizi ples je konceptualiziran kao vrsta "igre" koja ima svoje izazove jer je definirana određenim pravilima, običajima i standardima. Bez obzira na to podrazumijeva li iskustvo korištenje droga, određeni broj mladih ljudi koji prakticiraju cjelonoćno, a ponekad i višednevno plesanje uz različite stilove elektronske glazbe, doživjet će ono što svojevrstan pomak od svakidašnjega i uobičajenoga, a efekt takvoga doživljaja neće nužno ostati u ograničenom vremenskom okviru samoga partyja, nego će utjecati na transformaciju identiteta koja podrazumijeva restrukturiranje dotadašnjih znanja, stavova i emocija kroz inkorporaciju simboličkih i iskustvenih značenja stečenih kroz prakse rave-kulture. Prakse i tehnike koje konstituiraju speci- 
fičan oblik socijalizacije u klubu prenose se i na druge aspekte svakodnevnoga života mladih jer svojim efektima participiraju u procesu konstrukcije identiteta i utječu na doživljaj i definiciju zajedništva i pripadnosti i izvan trenutačnoga ekstatičnoga stanja tijekom rave-partyja.

\section{Zaključno}

Odmicanje od stroge klasne analize kao temelja subkulturnih studija birminghamske škole dovelo je, početkom devedesetih godina, do tzv. postsubkulturne teorije koja i poput birmingamske tradicije, ne predstavlja ujednačen i homogen teorijski opus, nego se odnosi na niz koncepata i teorija različitih dometa te na analize koje predmetu istraživanja pristupaju iz različitih teorijski pozicija. Kritike birminghamske škole i postulata kojima je definiran sam pojam subkulture sedamdesetih godina, uslijedile su kao odgovor na registraciju novih mreža odnosa i drugačijih oblika mladenačkih (sub)kulturnih saveza koji su se u prvom redu, ranih devedesetih, odnosili na elektronsku glazbu i kulturu koja je oko nje nastajala. Iako je jedan dio teoretičara koristio rave-kulturu kao poligon za hvatanje u koštac sa širim teorijskim pitanjima i problemima, neki su se odlučili za mikroanalize, bliže interakcionističkom pristupu, koje se odnose na detaljnije razmatranje specifičnih rituala i kulturnih obrazaca koji definiraju svijet elektronske glazbe, te značenja koje sami akteri na sceni pridaju određenim subkulturnim praksama. Iako su plesanje i konzumacija različitih droga također bili specifikum i nekih prethodnih subkulturnih grupa posredovanih glazbom i stilom, u specifičnom kontekstu rave-kulture te su prakse potaknule otvaranje prostora za drukčiju analizu i razumijevanje uloga koje takve prakse mogu imati u procesu konstrukcije identiteta ili trenutačnih identifikacija. Kao što je već napomenuto, postbirminghamske studije donijele su niz pristupa čija se raznovrsnost očituje i u različitom pogledu na prirodu i značenje određenih suvremenih (sub)kulturnih praksi, pa tako i ples i konzumacija droga u kontekstu rave-kulture bivaju interpretirani kroz različite teorijske prizme. Iako neke postsubkulturne interpretacije ostaju "zarobljene" unutar funkcionalističkoga okvira, sugerirajući kako je ples u rave-kulturi oslabljen jer nema nikakvu racionalnu funkciju, ili je "prazan" jer mu nedostaje "stvaran" subverzivni potencijal, a u kontekstu konzumacije droga naglašavaju isključivo ispraznu, eskapističku narav takvih praksi, neki će koncepti ipak otići dalje, tražeći značenje izvan okvira konvencionalnoga shvaćanja otpora, upozoravajući na važnost subjektivne dimenzije iskustva uvažavanjem interpretacija koje sami akteri pridaju (sub)kulturnim praksama u kojima sudjeluju. A upravo je takvo pristupanje problemu ključno ako se žele razumjeti kompleksna značenja koja proizlaze iz takvih ekspresivnih rituala, a koja su usko vezana za specifične kontekste, te ne podliježu teorijskom uopćavanju, pogotovo s obzirom na složene procese fragmentacije i hijerarhizacije koji se odvijaju unutar rave-kulture posljednjih dvadeset godina. 


\section{Literatura}

1. Anderson, T. L. and Kavanaugh, R. P. (2008). Solidarity and Drug Use in the Electronic Dance Music Scene. The Sociological Quarterly, 49: 181-208.

2. Becker, H. (1997). The Culture of the Deviant Group: The „jazz“ musician, in: Gelder, K. and Thornton, S. (Eds.). Subcultures Reader. London \& NY: Routledge.

3. Bennett,A. (1999). Subcultures or Neo-Tribes? Rethinking the Relationship Between Youth, Style and Musical Taste. Sociology, 33 (3): 599-617.

4. Bernschneider, S. and Freudmann, O. (2006). The Origin of MDMA ("Ecstasy"): Separating the Facts Fromthe Myths. Pharmazie, 61 (11): 966-972.

5. Butler, J. (1990). Gender Trouble: Feminism and the Subversion of Identity. London: Routledge.

6. Collin, M. and Godfrey, J. (1997). Alterd State. London: Serpent's Tail.

7. Derrida, J. (1991). Choreographies, in: Kamuf, P. (Ed.). A Derrida Reader: Between the Blinds. New York: Harvester Wheasheaf.

8. Gilbert, J. and Pearson, E. (1999). Discographies: Dance Music, Culture and the Politics of Sound. London and New York: Routledge.

9. Gore, G. (1997). The Beat Goes On: Trance, Dance and Tribalism in Rave Culture, in: Thomas, H. (Ed.). Dance in the City. New York: Macmillan.

10. Greer, G. and Tolbert, R. (1998). A Method of Conducting Therapeutic Sessions with MDMA. Journal of Psychoactive Drugs, 30 (4): 371-379.

11. Hanna, J. L. (1987). To Dance is Human: A Theory of Nonverbal Communication. Chicago: University of Chicago Press.

12. Hutson, S. R. (1997). Technosamanism: Spiritual Healingin Rave Subculture. Popular Music and Society, 23 (3): 53-77.

13. Irigaray, L. (1989). The Gesturein Psychoanalysis, in: Brennan, T. (Ed.). Between Feminism and Psychoanalysis. London \& New York: Routledge.

14. Malbon, B. (1999). Clubbing: Dancing, Ecstacy and Vitality. London \& New York: Routledge.

15. Melechi, A. (1993). The Ectasy of Disappereance, in: Redhead, S. (Ed.). Rave Off: Politics and Deviance in Contemporary Youth Culture. Aldershot: Avebury.

16. Mignon, P. (1993). Drugs and Popular Music: The Democratisation of Bohemia, in: Redhead, S. (Ed.). Rave Off: Politics and Deviance in Contemporary Youth Culture. Aldershot: Avebury.

17. Moore, K. and Miles, S. (2004). Young People, Dance and the Sub-Cultural Consumption of Drugs. Addiction Research and Theory, 12 (6): 507-523.

18. Mosler, D. (2001). Club Drugs. Law Enforcement Quarterly, 30: 5-10.

19. Parker, H.; Aldridge, J. and Measham, F. (1998). Illegal Leisure: the normalization of recreational drug use. London: Routledge.

20. Perasović, B. (2001). Urbana plemena: Sociologija subkultura u Hrvatskoj. Zagreb: Hrvatska sveučilišna naklada.

21. Pini, M. (1997). Cyborgs, Nomads and Raving Feminine, in: Thomas, H. (Ed.). Dance in the City. New York: Macmillan.

22. Pušnik, M. and Sicherl, K. (2010). Relocating and Personalising Salsa in Slovenia: To Dance is to Communicate. Antropological Notebooks, 16 (3): 107-123.

23. Redhead, S. (1993). The politics of Ecstacy, in: Redhead, S. (Ed.). Rave Off: Politics and Deviance in Contemporary Youth Culture. Aldershot: Avebury. 
24. Reynolds, S. (1997). Rave Culture: Living Dream or Living Death, in: Redhead, S.; Wynne, D. and O`Connor, J. (Eds.). The Club cultures Reader: Readings in Popular Cultural Studies. Oxford: Blackwell.

25. Rietveld, H. (1998). Repetitive beats: free parties and the politics of contemporary DIY dance culture in Britain, in: McKay, G. (Ed.). DIY Culture: Party and Protest in Nineties Britain. London: Verso.

26. Saunders, N. (1997). Ecstacy Reconsider. London: Neal`s Yard Press.

27. Shulgin, A. and Shulgin, A. (1993). PHIKAL. Berkeley: Transform Press.

28. Sparshott, A. (1995). A Measured Pace. Toronto: University of Toronto

29. Thornton, S. (1996). Club Cultures: Music, Media and Subcultural Capital. Middletown: Wesleyan University Press.

30. Ueno, T. (2003). Unlearning Raver: Techno- Party as the Contact Zone in TransLocal Formations, in: Muggleton, D. and Weinzierl, R. (Eds.). The Post-Subcultures Reader. Oxford: Berg.

31. Ward, A. (1997). Dancing around Meaning (And the Meaning around Dance), in: Thomas, H. (Ed.). Dance in the City. New York: Macmillan.

32. Wright, M. A. (1998). The Great British Ecstacy Revolution, in: McKay, G. (Ed.). DIY Culture: Partyand Protest in Nineties Britain. London: Verso.

33. Yacoubian, G.; Miller, S.; Pianim, S.; Kunz, M.; Orrick, E.; Link, T.; Palacios, R. V.; Peters, R. J. (2004). Towards and Ecstacy and Other Club Drugs: Pervention Intervention for Rave Attendees. Journal of Drug Education, 34: 41-59. 
Izvorni znanstveni rad

Rašeljka Krnić

Institute of Social Sciences Ivo Pilar, Zagreb, Croatia

e-mail: raseljka.krnic@pilar.hr

\title{
Dance and Drug Consumption in Rave Culture Sociology
}

\begin{abstract}
The need to modify or discard the term subculture appears in the early nineties, mainly as a reaction to the appearance of electronic dance music and the culture springing around it. This is the very example for the thesis about the changeable and complex nature of contemporary youth cultural practices, forms and styles, which require a new perspective and analytic tools to be understood. Apart from using rave culture and various electronic music scenes as a "field" on which to question the postulates of the Birmingham interpretation of subcultures within the framework of a broader theoretical discussion about the applicability of general terms such as class, resistance, style, etc., some authors have analyzed the specific elements that constitute this microcosm by attempting to reconstruct the organizational logic, practices, motives and "feeling structures" behind this youth movement. This paper is an overview and analysis of certain post-subcultural concepts, which, from different perspectives and different theoretical positions, analyse the two most important (sub)cultural practices that define the world of electronic music and rave culture - drug consumption and dance.
\end{abstract}

Key words: post-subcultural theory, rave culture, electronic music, ecstasy, drugs, dance. 